\title{
Study on the Development of Humanistic Tourism Resources in the Development of Tourism Industry
}

\author{
Jufang Zhou \\ Weinan Normal University, Weinan, Shaanxi, 714000
}

\author{
Keywords: Tourism Industry; Humanistic Tourism; Resource Development; Problem Analysis
}

\begin{abstract}
Humanistic tourism resources are the things and factors that have the function of tourism by mankind's creation, reaction times, national politics, economic culture, social customs. Its main contents include people's life, historical relics, culture and arts, ethnic customs, cultural landscapes, social environment Etc., different regions have different traditional features for tourists to watch. It can be seen from this that the humanistic tourism resources collectively reflect the style of a certain region and nation and are the crystallization of human history and culture. Then in the development process of humanistic tourism resources, there are still many problems affected by various realistic factors, and the research problems can better solve the problems and achieve the sustainable development of the humanistic tourism industry. The article summarizes the connotation of humanistic tourism, analyzes the existing problems in the development of humanistic tourism resources and proposes specific solutions.
\end{abstract}

\section{Introduction}

To a certain extent, humane tourism is a kind of tourism activity which not only includes other characteristics of tourism, but also reflects its own unique characteristics. Compared with the natural landscape tourism, humane tourism is an experiential tourism activity. Participate in tourism projects, in order to better understand the cultural connotation of a region, so more emphasis on humanistic tourism visitors physical difficulties. Thus, humanistic tourism is concerned with the spiritual world of tourists, and the exchange and communication between tourism projects and tourists are two-way. Tourism projects will invade tourists. Therefore, we must do a good job in regional culture protection in cultural tourism projects. The existing forms of humanistic tourism resources include the intangible resources such as villages, buildings, food, custom etiquette, national traditions and other intangible resources including life style, myths, folk songs and dances, ethnic beliefs and legends. The main contents include the following aspects:

First of all, it has rich and heavy historical implications. Our country has a history of five thousand years of humanities and has left a large number of ruins, architectural gardens, culture and arts, religious culture, engineering relics and so on during the course of national development. Tourists can watch such cultural landscapes to understand the politics and economy of different historical periods, Culture, science and technology and social outlook, discovering the law of human history and gaining rich historical knowledge. Second, the distinctive geographical and cultural characteristics. The vast territory of our country contains 56 ethnic groups. There is a great social and cultural difference among all ethnic groups. There is no exaggeration about the "one hundred customs, one folk custom, one ten nostalgia." This difference in regional culture makes tourists from all over the world more willing to cooperate with other ethnic groups to communicate and understand their national culture, it is these distinctive geographical and cultural colors that are highly attractive to tourists. Finally, a deep ideological mark. The development of human ideology is an important part of the development of human civilization. The ideological reaction acts objectively and reflects the obvious function of consciousness and initiative. Many of China's traditional concepts have infiltrated China's architectural, artistic and pictorial works of art, and religious ideology has become more prominent. It has a powerful appeal and a wide range of distribution. Religious and human resources not only have extremely high aesthetics Value, and 
create a mysterious, novel mood, it will also have a strong appeal to tourists.

\section{The development of human tourism resources problems}

The development of the tourism industry shows a certain degree of profitability. Too much attention to the interests will make the tourism project lose its original humanistic function. However, there are still some problems in the development of the humanistic tourism resources, as follows:

The development of cultural tourism resources should be based on geographical features, ethnic characteristics and cultural characteristics. However, the development of cultural tourism resources in many regions is more and more impacted by foreign cultures. Some original ecological cultures are on the verge of extinction. Some tourism project developers in pursuit of greater economic efficiency ignoring the profound connotation of the national culture blindly transform the national culture, some folk village experience the project folk customs, festivals and other procedural, standardized transformation, this transformation just ignoring the national The breath of life makes the tourism experience project suspenseful, tourists experience poor. Some developers and stakeholders of tourism projects have seriously damaged the living environment of local people through predatory exploitation of resources. For example, the construction of man-made landscapes and leisure clubs around a certain historical and cultural sites and ruins has undermined the original nature of the landscape Sexual, original ecology is not conducive to the sustainable development of humanistic tourism.

The further promotion of urbanization in our country has led to the emergence of various historical and cultural cities in various places. Some of the small, medium-sized historical and cultural cities blindly pursue the development plan of "jumping out of the ancient city and building a new district" from the original "antique modernization" to the present Expansion of urban space, making a lot of historical and cultural city of the great changes have taken place, the most common way is to dismantle the city's old buildings, changing the original pattern of the ancient city and the streets and alleys, blindly highlight the modern construction pattern and style, and excessive light Chemical engineering has made many ancient cities lost ancient charm; and the construction of the new city and the overall style of the ancient city out of phase, resulting in the entire ancient city architectural style there is "the ancient city without rhyme, Metro no character" embarrassing situation. For example, some of the ancient cities have extremely high population density and various antique constructions. The so-called antique is only a residential building with antique elements such as carved wood or glass roof. The modern signage and lighting project make the real ancient buildings Public, this lack of planning project development can not make tourists truly feel the charm and mood of the ancient city, making the cultural tourism project has lost its core soul.

Tourists go home to travel around the souvenirs are similar, just shows the lack of humanistic tourism project features: First, the cultural tourism product features a single, tourist participation, poor experience. Many tourism projects are based on visual products, product features a single, for visitors to participate in, the experience of the project rarely. Second, the humanistic tourism products are poor in system and integrity. Some cities scattered tourist attractions, can not form a clustering effect, a direct impact on tourists' travel experience. Finally, the lack of high-end travel goods. As an important component of tourism products, tourism products are an important channel to increase tourism projects. However, tourism products in many parts of our country are diverse in scope but lacking in advanced and high-end tourism products, large industries and high starting-point brands. All of a sudden, the lack of in-depth mining talent development of cultural heritage products, resulting in the lack of creative travel products, the market is small, thin profits.

\section{The development strategy of humanistic tourism resources}

In view of the existing problems in the development of humanistic tourism resources, it is suggested to improve from the following aspects:

To a certain extent, national culture belongs to the part of natural ecosystem. Any cultural 
ecology does not exist independently, but is an organic combination of nature and humanity. Only when it is integrated into the natural environment can the humanistic value of the humanistic landscape More prominence, it is necessary to strengthen the protective development of cultural tourism resources. Highlighting the originality, completeness and diversity of cultural resources. The lifestyles, eating habits, architectural costumes, and production techniques of different ethnic groups formed under specific geographical environment are important continuations of national culture. The main purpose of tourist travel is to experience Different cultural customs. In the actual development process, we should try our best to maintain the original appearance of local cultural resources and highlight the local features. We should not weaken the connotation of cultural resources in order to over-cater to market and consumers, and avoid the vulgar and over-commercialization of cultural tourism resources. At the same time, it should give full consideration to expanding the living space of cultural resources in order to achieve the inheritance and development of traditional ethnic culture and create new values for traditional culture while creating economic value.

The development of humanistic tourism resources should highlight the regional characteristics, ethnic characteristics and traditional features, excavate the cultural connotations in depth, and enhance the cultural taste of scenic spots and tourist products so as to enhance the plasticity of tourism products and tourism projects and attract more tourists to travel. In the process of development, we should not only develop the project on the surface features of humanistic tourism resources in order to avoid the one-sided and shallow superficial development of human resources tourism. We should excavate the cultural connotation of humanistic tourism resources from the outside to the inside and enhance the external taste of the project through the connotation, Making the internal culture and external landscape form an organic whole. On the one hand, it is necessary to emphasize the planning of participatory cultural tourism projects to meet the ever-increasing demands of tourists for tourism services. Such as Shaoxing, "Lu font number" series of tourism product development has achieved greater success, Shaoxing Culture and Tourism Group launched the "follow the textbook tour Shaoxing" project features are very prominent. However, in-depth analysis of the project can also be further expanded and enriched on this basis, for example, the project can change the original tourist simple, mechanical forms of tourism, to carry out a variety of activities, such as allowing visitors to experience Lu Xun Baicao Park Describing the pastoral delights and simulating Lu Xun's reading in Sanwei Bookstore, experts and scholars can also be invited to hold seminars on the work of Lu Xun. A rich and vivid activity can enhance tourists' travel experience and create a more direct and intuitive understanding of Lu Xun's works. On the other hand, it is necessary to improve the taste of tourist products and develop more high-end and more distinctive cultural products. Such as Kaifeng, "Yu Travels" has become the city of Kaifeng, a small well-known tourist products around the city, which Kaifeng in Henan cultural characteristics of product development, sales, products include traditional costumes, rust, chrysanthemum tea and other unique local characteristics Products, and packaging high-end, so considerable benefits. In addition, Shaoxing's "Lushao" product, for example, can be used to produce beautiful miniature landscapes such as Baicao Garden, Sanwei Bookstore, and social drama, or to show classic novels such as Ah Q and Xianglinsao in the form of puppets and clay sculptures in the image of characters. Only by continuously excavating the connotation of the local cultural tourism resources can we finally achieve the win-win economic and social benefits.

The overall planning of humane tourism resources can break the bad competition among the scenic spots and implement the differentiation strategy of tourism product development. The actual work should do the following two aspects: on the one hand, it is necessary to implement regional linkage and implement the whole with other scenic spots Development and formation of eco-cultural industry cluster area; cooperation with other scenic spots to develop humanistic tourism projects, expanding tourist attractions market, achieve mutual response landscape, and ultimately achieve the joint development of tourism resources. On the other hand, government departments should take the lead to actively coordinate various stakeholders, including various government departments, scenic spot contractors, tourism development companies, private enterprises and local 
residents; strengthen communication with cultural relics protection departments and realize humanistic tourism resources Activation and so on.

In short, with the continuous improvement of people's living standards in recent years, the tourism industry has gradually become one of the fastest growing economic industries in our country. However, the exuberant tourism demand has made the services of many tourist attractions unable to meet the ever-increasing demands of tourists. Leading to the decline in tourist quality and tourist satisfaction. Moreover, the fashion of tourism is constantly changing and the structure of tourism consumption is becoming more and more diversified. Only by continuously developing more and more high-standard and diversified tourism projects can tourists satisfy ever-increasing demands for tourism Development needs. In the process of developing actual cultural tourism resources, we must continuously improve the taste and connotation of tourism projects based on the overall planning of resources and do a good job of protective development so as to achieve the sustainable development of China's cultural tourism industry.

\section{References}

[1] Chris Ryan, Gu Huimin. The Social Impact of Tourism on Beijing Interoperability - A Case Study of Environmental Changes [J]. China Tourism Research, 2017, (6).

[2] Lei Guoxiong. Based on the context, the pulse of regional tourism brand image management research [D] Wuhan University, 2015.

[3] Luo Yanju. Some Theoretical Studies on Non-Optimal Tourism Resources [J]. Arc Resources and Environment, 2015, (9).

[4] Hu Fen, Yuan Jun.Internal mechanism and cultivation strategies of eco-cluster in regional tourism industry [J]. World Geography, 2016, (6).

[5] Li Donghe, Zhao Yuzong. Research on Tourism Spatial Expansion Strategy of Non-Metropolitan Tourist Resources - A Case Study of Hefei, Anhui Province [J]. Beijing Foreign Affairs University Journal, 2017-07-08.

[6] Xu Chunxiao. On non-optimal tourism resources compensation types and nature of [J]. Journal of Social Sciences of Hunan Normal University, 2015, (4).

[7] Cui Xiaoming, Zhang Hong. Ankang Tourism Image Positioning [J]. Ankang University Journal, 2017, (1). 